\title{
Qualitative phytochemical analysis for isolation of terpens from Clerodendron infortunatum leaves
}

\author{
Dr.Rimjhim Sheel ${ }^{1}$ and Kumari Nisha ${ }^{2}$ \\ ${ }^{1}$ Associate Professor, Dept. of Botany, Ganga Devi Mahila College ,Kankarbagh Patna- 800020. \\ ${ }^{2}$ Research Scholar ,Dept. of Biotechnology, College of Commerce, Patna.
}

\begin{abstract}
Qualitative phytochemical analysis of the plant Clerodendron infortunatum confirms the presence of various phytochemicals like terpens, carbohydrates, glycosides, saponin, in its hexane extracts. The present investigation deals with the presence of these phytochemicals by phytochemical analysis of leaves of medicinally active plant for purification of bioactive constituents terpene. In the field of phytochemistry, it is necessary to choose solvent according to biological activity required. This preliminary study draws attention to the need for further studies of the active principles identified in the reported species for the treatment of many diseases as well as to understand their mode of action in controlling diseases.
\end{abstract}

Keywords: Phytochemical; Clerodendron infortunatum; Hexane Extract; Methanolic phase.

\section{Introduction}

The plant Clerodendron infortunatum belongs to the genus Clerodendron (family Verbenaceae) and is extensively distributed in tropical and subtropical regions of the world. The genus was reported by Linnaeus in 1753. About two centuries later, in 1942 Moldenke, readopted the Latinized name 'Clerodendrum', which is now presently used by taxonomists for the classification of the genus and species. The genus is comprised of small trees, herbs or shrubs which flower during February and May (Haines, 1925). The Clerodendron is known as "Bharhi"," Bhrigubhava" , "Padma" , "Fanji" , and "Brahman yastika" in Sanskrit (Shasthri,1977), as "Peruvelum" in Kerela, and as "Bhant" or "Bharangi" in Hindi. More than 500 species of the genus Clerodendrum are identified till now.

It is variously used in ayurvedic, unani and homeopathy system of medicine in case of ailments. The plant kingdom has proven to be most useful in the treatment of diseases. They are also an important source of phytochemicals for the world's pharmaceuticals. The leaves and roots of the plant are employed externally for tumour and certain skin disease, and internally as tonics (Maisch,1885). Phyto-medical importance of various species of Clerodendrum genus has been reported in various indigenous systems of ayurvedic, unani medicines. This genus is being used specifically in Indian, Chinese, Thai, Korean, Japanese systems of medicine for the treatment of various diseases such as syphilis, typhoid, cancer, jaundice and hypertension. The powder or paste form of the extracts of root, stem and leaves of this genus are reported to be used as medicine for the treatment of asthma, pyreticosis, cataract, malaria, and diseases of blood, skin and lung. It is also used in folklore remedies.

Plants in all facets of life have served a valuable starting material for drug development. Phytochemicals are used as templates for lead optimization programs, which are intended to make safe and effective drugs. Plants contain many active compounds such as

alkaloids, terpinoides, steroids, tannins, glycosides, volatile oils, fixed oils, resins, phenols and flavonoids which are deposited in their specific parts such as leaves, flowers, bark, seeds, fruits, root, etc. The beneficial medicinal effects of plant materials typically result from the combination of these secondary products (Tonthubthimthong et al., 2001). In 1985 Farnsworth et al., identified 119 secondary plant metabolites which were used as drugs. Phytochemicals are known to possess antioxidant (Wong et al., 2009), antibacterial (Nair et al., 2005), antifungal (Khan and Wassilew, 1987), antidiabetic (Singh and Gupta, 2007; Kumar et al., 2008a), anti-inflammatory (Kumar et al., 2008b), and radio-protective activity (Jagetia et al., 2005), and due to these properties they are largely used for medicinal purpose.

Terpene are one of the important bioactive constituents of plants. Terpene of this plant has been recognized as an effective anti-tumour molecules. Diterpenoid (Clerodin) is used to cure carcinoma in human (Barton et.al 1961). The methanolic extract of Clerodendron infortunatum leaves posses a high amount of bioactive compounds other then terpenoids i.e. sterols, alkaloids, carbohydrates, glycoside, and tannins(Sheel and Nisha, 2014). Hence the isolation and detection of terpen is difficult. Therefore, qualitative phytochemical screening of medicinal plants are necessary by using different solvents, as they possess a less amount of bioactive compounds. Recently the studies of medicinal plants have attracted the Scientists in finding the solution to the problem occurring by the use of antibiotics. The present study is designed for Isolation of the 
bioactive chemical constituent, terpenes, commonly used as medicine in India, in the hexane extract from leaves of Clerodendron infortunatum.

\section{Materials and methods}

The plant specimen were collected from the road side of Arrah and Koilwar in Bihar. By the side of the road, abundant population of the plant Clerodendron infortunatum (shrub) is present. Leaves of Clerodendron infortunatum plants were separated, washed carefully with tap water, rinsed with distilled water, air dried for 1 hour, and shade dried. They were ground in to powder (coarsely) and stored at room temperature. The extract of the samples were prepared by soaking $100 \mathrm{gm}$ of dried powder in $200 \mathrm{ml}$ of Hexane for 32 hours. The extracts were filtered using Whatman filter paper No. 42. Methodology was performed in two steps.

\section{Step 1: phytochemical tests of Hexane extract.}

Following tests were performed for qualitative detection of phytochemicals in extract.

\section{Test for Sterols:}

Salkowski test: $2 \mathrm{ml}$ of extract was mixed with $2 \mathrm{ml}$ of chloroform and $2 \mathrm{ml}$ of concentrated $\mathrm{H}_{2} \mathrm{SO}_{4}$ was added carefully and shaken well. The chloroform layer did not appeared red and acid layer fluorescent greenish yellow. This strongly supports the absence of sterols from the extract.

\section{Test for Terpinoids:}

Salkowski test: $2 \mathrm{ml}$ of extract was mixed with $2 \mathrm{ml}$ chloroform and $3 \mathrm{ml}$ concentrated $\mathrm{H}_{2} \mathrm{SO}_{4}$ was added carefully and shaken well. Positive result for the presence of terpinoides was noted by the appearance of reddish brown colour of interphase.

\section{Test for Alkaloids}

Mayer's test: Extract was warmed with $2 \% \mathrm{H}_{2} \mathrm{SO}_{4}$ for two minutes, filtered and few drops of Mayer's reagents were added. White coloured precipitation did not appeared giving a negative result.

Mayer's reagent preparation:

Solution (A) dissolved $1.36 \mathrm{~g}$ mercuric chloride in $60 \mathrm{ml}$ of distilled water.

(B) Dissolved $5 \mathrm{~g}$ of potassium iodide in $20 \mathrm{ml}$ distilled water. Mix A and B and adjust the volume to $100 \mathrm{ml}$ with the help of distilled water.

\section{Test for flavonoides:}

Ammonium Test: A small quantity of the extracts heated with $10 \mathrm{ml}$ of ethyl acetate in boiling water for 3 minutes. The mixture filtered and the filtrate was shaken with $1 \mathrm{ml}$ of dilute ammonia solution (1\%). The layers were allowed to separate. Waited for colouration in Ammonia layer. Yellow colouration at ammonia layer was not observed which indicates the absence of flavonoides from the extract.

\section{Test for Carbohydrate:}

Fehling Test: Equal quantity of Fehling solution A and Fehling solution B are mixed and few drops of extract was added and boiled. Brick red precipitate of cuprous oxide confirms the presence of carbohydrate.

\section{Test for Tannins:}

Ferric Chloride Test: A small quantity of the extract was boiled with $5 \mathrm{ml}$ of $45 \%$ ethanol for 5 minutes. The mixture was cooled and filtered. $1 \mathrm{ml}$ each of filtrate diluted with distilled water and two drops of ferric chloride was added and waited for colouration. A transient green to black colour did not appeared, hence giving a negative result.

\section{Test for Phenols:}

Ellagic Acid Test: The test solution was treated with few drops of 5\% (w/v) glacial acetic acid and 5\% (w/v) $\mathrm{NaNO}_{2}$ solution. Niger brown precipitate did not occur nor the solution turned muddy. Hence the absence of Phenols were observed from the extract.

\section{Test for Glycosides:}

Concentrate $\mathrm{H}_{2} \mathrm{SO}_{4}$ Test: In $5 \mathrm{ml}$ extract, $2 \mathrm{ml}$ glacial acetic acid, one drop of $5 \% \mathrm{FeCl}_{3}$ and conc. $\mathrm{H}_{2} \mathrm{SO}_{4}$ was added. The brown ring colouration in interphase marks the presence of Glycosides. 


\section{Test for Protein:}

Biuret Test: $2 \mathrm{ml}$ of Biuret reagent was added to $2 \mathrm{ml}$ of extract. The mixture was shaked well and warmed on water bath. Absence of protein was noted as violate colouration was not observed.

\section{Test for Saponin:}

Foam Test: The extract was diluted with $20 \mathrm{ml}$ of distilled water and it was shaken in a graduated cylinder for 15 minutes. A thin foam layer was observed. This indicates that Saponin is weakly present in the extract. After screening hexane extract $(100 \mathrm{ml})$ was evaporated under refrigerator and crystals were obtained.

\section{Step 2; Qualitative tests after first partition:}

The obtained crystals were weighed and partitioned in 1:1 Hexane-Methanol (10ml each) mixture. Methanolic phase was separated carefully with the help of micropipette and transferred in to fresh and sterile test tube. The qualitative phytochemical tests of methanolic phase was again performed. Only four phytochemical tests were performed in this step which gave positive result in previous step i.e. Salkowaski test, (for terpene detection), Fehling test (for carbohydrate detection), Conc. $\mathrm{H}_{2} \mathrm{So}_{4}$ test (for Glycoside detection), Foam test (for Saponin detection). Same procedure was followed as mentioned in step1. The phytochemical analysis of the methanolic phase shows that Terpene is strongly present, Glycosides are weakly present and Carbohydrate is mildly present. Whereas Saponin gave negative result.

\section{Step 3; Qualitative tests after Second partition:}

The remaining methanolic test sample was evaporated under refrigerator and crystals were obtained. Obtained crystals were weighed and partitioned with 1:1 Ethyl acetate and water. Ethyl acetate phase was separated carefully with the help of micropipette and transferred into a fresh sterilized test tube. Three tests which gave positive result in methanolic phase i.e. Salkowaski test (for terpene detection), Fehling solution test (for carbohydrate detection) and Conc. $\mathrm{H}_{2} \mathrm{So}_{4}$ test (for Glycosides detection) were followed in ethyl acetate phase, same as previous. In this step Terpens were strongly present whereas Glycosides were mildly present and Carbohydrates were absent .

\section{Results and discussion}

While performing the phytochemical analysis of Hexane extract, chloroform layer did not appeared red, in Salkowski test which indicates the absence of sterol. But a reddish brown coloration in the interface was seen which indicates positive result for the presence of terpenes. White colour ppt. in Mayer test indicate the presence of alkaloids. But no such precipitation was observed. This shows the absence of alkaloids. In Ammonia test yellow colour was not seen in ammonia layer, hence, confirms the absence of flavonoid whereas Brick red coloured precipitation in Fehling test strongly supports the presence of carbohydrate in the extract. Transient green to black in Ellagic acid test is the positive result for phenol, but hexane extract gives negative result. This indicates that Phenol is absent from the extract. Brown ring appeared in Conc $\mathrm{H}_{2} \mathrm{So}_{4}$, hence indicates the presence of glycosides in the Hexane extract. To confirm protein in the extract Biuret test was performed. Violate colour did not appeared which indicates the absence of protein. Weak foaming was also seen during Foam test indicating the presence of saponin.

Therefore, Hexane extract (Step-1) of Clerodendron infortunatum revealed the presence of phytochemicals i.e. Terpenes, Carbohydrate, Glycosides and Saponin. Whereas, after partition, Methanolic phase of Hexane extract (Step-2) contains maximum of terpenes and few quantity of glycosides and carbohydrate. In the last step(Step-3) phytochemical tests detects $99 \%$ of terpene and few quantity of glycoside.

Table 1: Qualitative phytochemical tests result for isolation of terpene from leaves of Clerodendron infortunatum

\begin{tabular}{|c|c|c|c|c|}
\hline S.No & Phytochemical & Step 1 result & Step 2 result & Step 3 result \\
\hline 1. & Sterol & - & - & - \\
\hline 2. & Terpene & ++ & +++ & +++ \\
\hline 3. & Alkaloid & - & - & - \\
\hline 4. & Flavonoid & - & - & - \\
\hline 5. & Carbohydrate & +++ & - & - \\
\hline 6. & Tannin & - & - & - \\
\hline 7. & Phenol & - & ++ & + \\
\hline 8. & Glycosides & +++ & - & - \\
\hline 9. & Protein & - & - & - \\
\hline 10. & Saponin & + & & \\
\hline
\end{tabular}




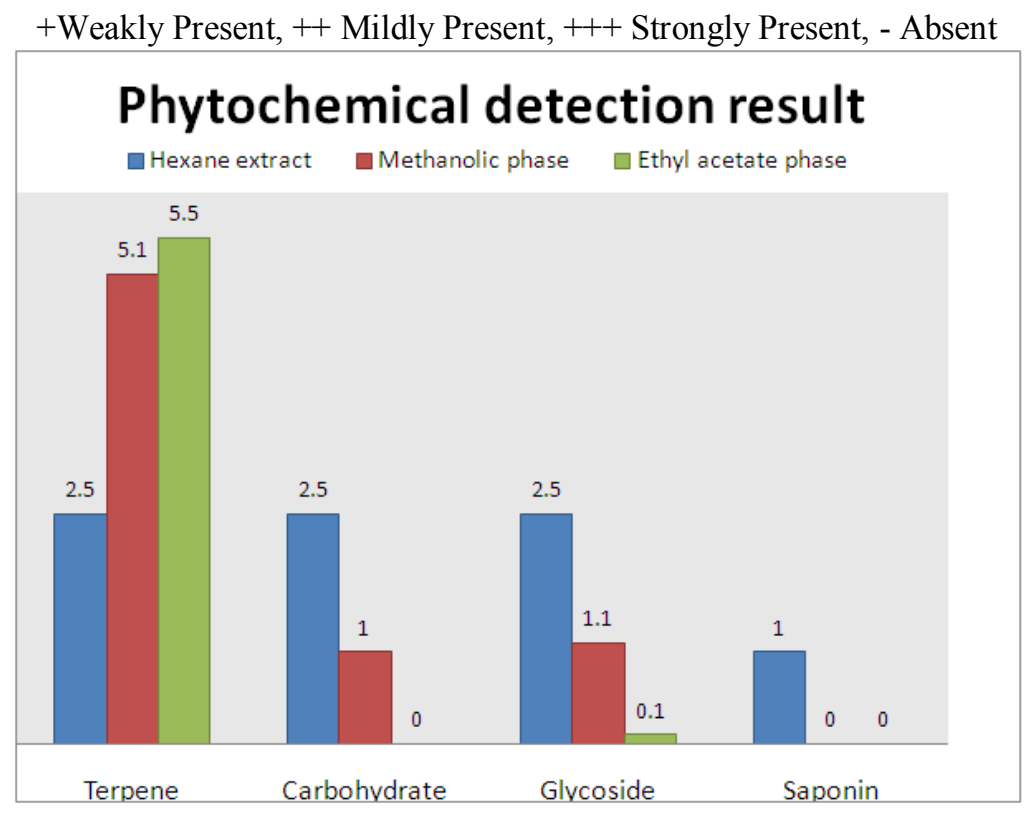

The considerable amount of Carbohydrate and Saponin is present in hexane extract, whereas these two constituents absent in the next step of terpene purification. Glycosides mildly present in second step and strongly present in hexane extract.

\section{Conclusion}

In the field of research of pharmacology, it is necessary to choose solvent according to biological activity required and not that which gives a high amount of bioactive compounds..The plants contain triterpenoids and diterpenoids shows antimicrobial activity against staphylococcus (Chung et al., 2011). From the present study it is found that crude extract express good biological capacity which indicates that the substance with powerful biological effect exists in this extract and must be isolated and purified to confirm its pharmacological and medicinal use. However, further studies are required in this direction for its comprehensive analysis including quantitative / semi quantitative analysis, characterizing its chemical structure and assessing its biological activities. In Clerodendron infortunatum the bioactive components Terpene, Carbohydrate, Glycosides and Saponin are soluble in hexane, but out of these four components, Terpenoids, Carbohydrate and Glycosides are soluble in methanolic phase and finally, ethyl acetate phase purifies the Terpenes. So, it is concluded that these solvents may be used for Terpenoid isolation, identification, purification, characterization and elucidation of the structure of the bioactive compounds of $C$. infortunatum that would be obtained with a view to obtain useful chemotherapeutic agent.

\section{Acknowledgement}

Authers are thankful to the management of Ganga Devi Mahila Mahavidyalaya for providing research facilities for this work.

\section{References}

[1]. Moldenke HN. Notes on the genus Clerodendrum (Verbenaceae). IV. Phytologia. 1985;57: 334-365.

[2]. Hsiao JY, Lin ML. A Chemotaxonomic study of essential oils from the leaves of genus Clerodendrum (Verbenaceae) native to Taiwan. Botany Bulletin Academica Sinica.1995;36: 247-251.

[3]. Steane DA, Scotland RW, Mabberley DJ, Olmstead RG. Molecular systematics of Clerodendrum (Lamiaceae): its sequences and total evidence. American Journal of Botany.1999; 86: 98-107.4.Shashtri, V.D., 1977 Bhavprakash Nighantu Motilal Banarsidas, New Delhi.

[4]. Maisch, J.M.1885 On some useful plants of the natural order of Verbenaceae. Americal Joural of pharmacy 57, Botanical medicine monographs and sundry

[5]. Clerodendrum and Heathcare: An Overview. Neeta Shrivastava, Tejas Patel. Medicinal and Aromatic Plant Science and Biotechnology 2007;1(1), 142-150.

[6]. Ajayi I. A., Ajibade O. and Oderinde R. A. Preliminary Phytochemical Analysis of some Plant Seeds. Res.J.Chem.Sci. 2011; 1(3):58-62.

[7]. Balunas MJ, Kinghorn AD. Drug discovery from medicinal plants. Life Sci 2005; 78:431-441.

[8]. Tonthubthimthong P, Chuaprasert S, Douglas P, Luewisuttichat W (2001) Supercritical CO2 extraction of nimbin from neem seeds an experimental study. Journal of Food Engineering. 47: 289-293.

[9]. Fransworth, N.R. Biological And Phytochemical Screening Of Plants, Journal Of Pharmaceutical Science.1996; Pp 55,225-227.

[10]. Nair R, KalariyaT, SumitraC, ( 2005). Antibacterial activity of some selected Indian medicinal flora.. Turkey Journal of Biology, 29: 41-47 
[11]. Khan M, Wassilew SW ( 1987) Natural pesticides from the neem tree and other tropical plants. (Eds) Schmutterer H and Asher KRS, Germany: Digitalverlag GmbH, 645-650.

[12]. Singh N and Gupta M (2007) Effect of ethanolic extract of Syzygium cumini seed powder on pancreatic islets of alloxen diabetic rats. Indian Journal of Experimental Biology, 45: 861-867.

[13]. Kumar A, Ilavarasan R, Jayachandran T, Deecaraman M, Aravindan P, Padmanabhan N, Krishan MRV (2008a) Anti diabetic activity of Syzygium cumini seed and its isolate compounds against streptozotocin induced diabetic rats. Journal of Medicinal Plants Research, 2(9): 246-249.

[14]. Kumar A, Ilavarasan R, Jayachandran T, Deecaraman M, Kumar MR, Aravindan P, Padmanabhan N, KrishanMRV(2008b) Anti inflammatory activity of Syzigium cumini seed. African Journal of Biotechnology, 7 (8): 941-943.

[15]. Jagetia G.C.,Baliga,M.S.,Venkatesh,P., (2005) Influence of seed extracts of S. cumini on mice exposed to different doses of $\gamma$ radiation. Journal of Radiation Research. 46 (1): 59-65.

[16]. Jagetia GC, Baliga MS, and Venkatesh P (2005) Influence of Seed Extract of Syzygium Cumini (Jamun) on Mice Exposed to Different Doses of $\gamma$-radiation. J Radiat Res (2005) 46 (1): 59-65. doi:10.1269/jrr.46.59

[17]. Barton, D.H.R., cheung H.T., cross, A.D., Jackman, L.M. and M. Martin Smith,M. 1961 Diterpenoid bitter principles, Part III. The constitution of clerodin. J. Chem. Soc 5061-5073, Dol: 10.1039/JR 9610005061.

[18]. Sheel R., Nisha K. and Kumar J. (2014) Preliminary Phytochemical Screening Of Methanolic Extract Of Clerodendron infortunatum.

[19]. Chung PY,Navaratnam P,and Chung LY(2011) Synergistic antimicrobial activity between pentacyclic triterpenoids and antibiotics against Staphylococcus aureus strains. Annals of Clinical Microbiology \& Antimicrbioals (2011) 10:25 doi:10.1186/1476-0711-1025 